\title{
User-friendly data portal provides access to a transient paleoclimate simulation covering the last 21 kyr
}

Oliver Timm ${ }^{1}$, A. Timmermann ${ }^{1}$ and S.H. DeCarlo ${ }^{1,2}$

'International Pacific Research Center, University of Hawai'i at Manoa, Honolulu, USA; timm@hawaii.edu ${ }^{2}$ Asia-Pacific Data-Research Center, University of Hawai'i at Manoa, Honolulu, USA

\section{Modern information technology facilitates access to large datasets from transient paleoclimate model simulations. A recently archived model simulation over the last $\mathbf{2 1} \mathrm{kyr}$ is now online and can be used by paleoclimatologists in their research activities.}

Modern paleoclimatology is built on decades of laborious field campaigns that have provided researchers with a spectacular proxy archive of Earth's past climate. With the upsurge in computer technologies, Global Climate Models (GCM) and Earth System Models of Intermediate Complexity (EMIC) have become fundamental tools in paleoclimate research. The synergy of the two disciplines (i.e., model and data) requires a mutual exchange of all forms of information. In particular, access to large volumes of model data poses a major challenge for many paleoresearchers.

Here, we describe a recently published 21 kyr transient paleo-simulation from the Last Glacial Maximum (LGM) to pre-industrial times that was conducted with an EMIC. The full set of ocean and atmospheric model data are now publicly available through a user-friendly data portal.

\section{Model simulation description}

The transient 21-kyr paleoclimate simulation was conducted with version 3 of the ECBilt-CLIO model (Opsteegh et al., 1998; Goosse and Fichefet, 1999). ECBilt-CLIO consists of three coupled subsystems: a simplified 3-layer global dynamical atmosphere, a 3D primitive equation global ocean model, and sea-ice component. The 3 components are coupled by exchange of momentum, heat, and freshwater. Sea ice is calculated from the surface heat fluxes and advection by the ocean circulation (thermodynamic-dynamic). Soil moisture and river runoff into the ocean close the hydrological cycle. A small correction in the freshwater flux is applied over the oceans, in order to correct for a modelspecific excessive precipitation over the $\mathrm{N}$. Atlantic and Arctic.

We increased the $\mathrm{CO}_{2}$ sensitivity of the standard version of the model to mimic that of state-of-the-art GCMs (Timm and Timmermann, 2007). The model was forced with time-dependent boundary conditions. Starting from an LGM equilibrium state, the orbital parameters are continuously updated according to Berger (1978). Atmospheric concentrations for
$\mathrm{CO}_{2}, \mathrm{CH}_{4}$ and $\mathrm{N}_{2} \mathrm{O}$ are prescribed following the time-evolution measured in Antarctic and Greenland ice cores. Ice-sheet related variations in topography and albedo for the period from $21 \mathrm{kyr}$ BP to present were included following the ICE4G reconstruction of Peltier (1994). Vegetation cover was not modified during this simulation (i.e., conditions were kept constant at the level of AD 1970). Millennial-scale variability, such as Heinrich event I, the Younger Dryas or the $8.2 \mathrm{kyr}$ BP event, were not included in this transient simulation. Therefore, the current model results are suitable for the study of orbitally controlled climate changes. Simulations with prescribed freshwater forcing in the N. Atlantic are currently in progress, which will allow the generation of millennial-scale variability in the model. More details about the model and the transient forcing can be found in Timm and Timmermann (2007), Timm et al. (2008) and Timmermann et al. (subm.).

\section{Accessing the data}

The atmospheric and oceanic data of the 21-kyr transient simulation can be accessed through the website of the AsiaPacific Data-Research Center (APDRC, see link below). The APDRC presently supports two access modes: Live Access Server (LAS) and Open-source Project for a Network Data Access Protocol (OPeNDAP). The LAS server is a user interface designed for the purpose of obtaining a quick graphical overview of gridded data fields (Fig. 1). For users not familiar with Ferret, Grid Analysis and Display System (GrADS) or Matrix Laboratory (MATLAB) software, the LAS interface to the 21-kyr transient paleosimulation (see link below) provides a comfortable way of generating time series for individual grid points (such as for sediment or ice core locations), Hovmoeller diagrams (for either longitude, latitude or depth sections), or longitude-latitude maps for individual times. Moreover, it is possible to compute longitude, latitude or time-averages over any of the data fields and compare different fields with each other (using the left access bar). In this way, the user can define their own datasets from the existing climate variables. Figure 1 illustrates some of the graphical capabilities of the LAS web-access to the 21-kyr transient paleo-model simulation (see link below for tutorial).

B) Timeseries Temperature $1200\left({ }^{\circ} \mathrm{C}\right)$
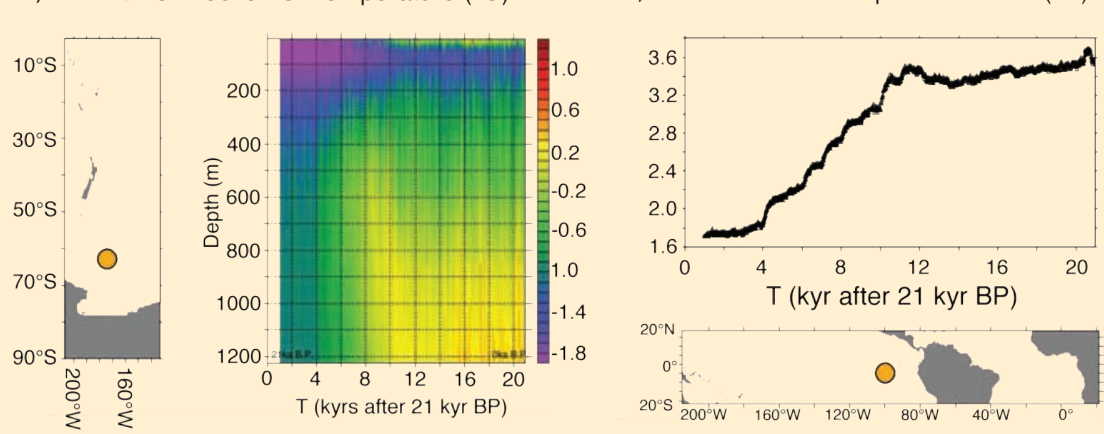

C) SST at $11 \mathrm{kyr} \mathrm{BP}\left({ }^{\circ} \mathrm{C}\right)$

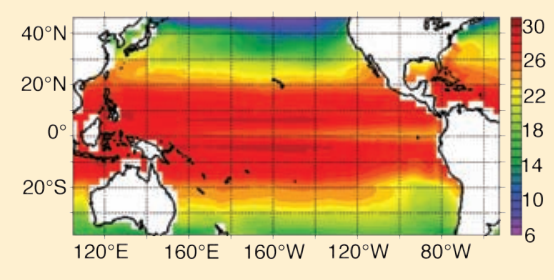

D) Y-T Hovmoeller of winds at $800 \mathrm{hPa}$

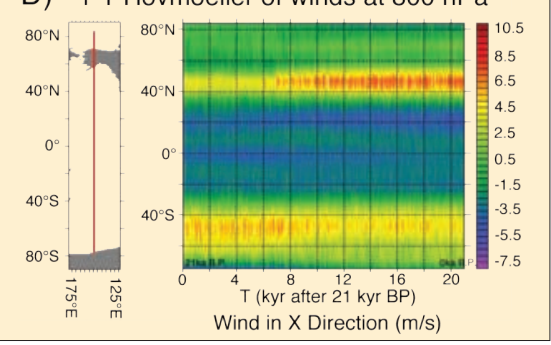

Figure 1: Illustration of the graphical capabilities of Live Access Server: $\boldsymbol{A})$ Depth-time Hovmoeller diagram for an upper ocean (to $1200 \mathrm{~m}$ depth) location (orange circle) south of New Zealand; $\boldsymbol{B}$ ) Time series of ocean temperature (at $1200 \mathrm{~m}$ depth) west of the Galapagos Islands (orange circle); C) Map of SST at $11 \mathrm{kyr}$ BP for Pacific region; $\boldsymbol{D}$ ) Latitude-time Hovmoeller diagram of zonal wind component at 154 W. Note: "O yr after 21 kyr BP" is 21 kyr BP. 


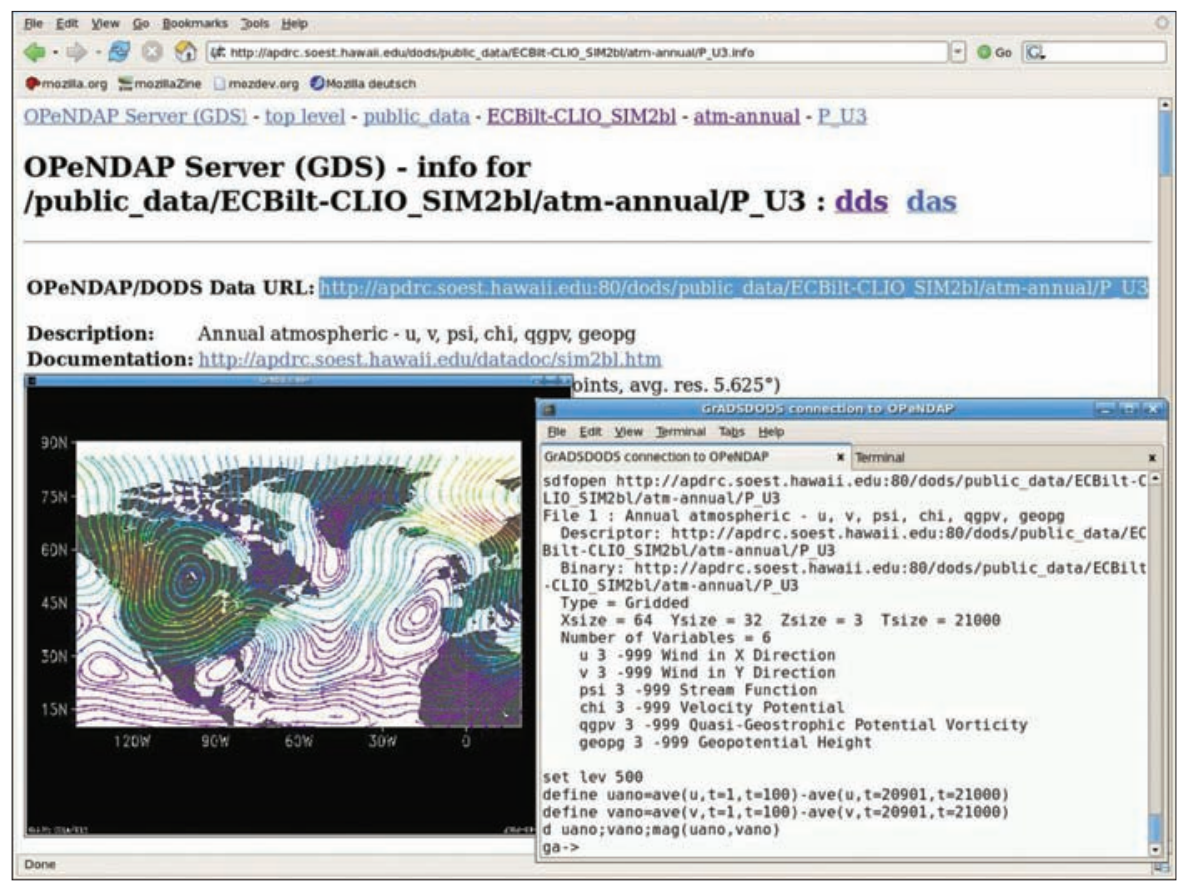

Figure 2: Screen shot of the direct integration of the atmospheric model data into GrADS through the OPENDAP server. Shown are the differences in the 500-hPa wind field (streamlines) between LGM and pre-industrial times.

In comparison, the OPeNDAP server allows researchers to work directly with the data within their data visualization/manipulation tools (e.g., GrADS, Ferret or MATLAB), provided their software version supports the OpeNDAP access of remote datasets.

When selecting OPeNDAP, the APDRC will guide the user through the oceanic/ atmospheric datasets to the sub-categories. By clicking on "info", the user can obtain the necessary URL and additional information on the variables in the dataset (see screen shot Fig. 2). The URL is needed to open a connection from the research- data sources will allow a deeper insight into the underlying physical mechanisms behind glacial-interglacial cycles and millennial-scale variability.

\section{Note}

APDRC: http://apdrc.soest.hawaii.edu/

Data portal to the $21 \mathrm{kyr}$ paleo-simulation: http://apdrc.soest.hawaii.edu/las/servlets/ dataset?dset=APDRC\%20PublicAccess $\% 20$ Products/ECBilt-CLIO\%20SIM2bl

Project page with description and tutorial examples: http://apdrc.soest.hawaii.edu/projects/ paleomodeling/index.html

\section{Acknowledgements}

This research was supported by NSF (grant ATM06-28393). Additional support was provided by the Japan Agency for Marine-Earth Science and Technology (JAMSTEC), NASA (grant NNX07AG53G), and NOAA (grant NA17RJ1230) through their sponsorship of research activities at the International Pacific Research Center.

\section{References}

Goosse, H. and Fichefet, T., 1999: Importance of ice-ocean interactions for the global ocean circulation: A model study, Journal of Geophysical Research,104(C10): 23337-23356, doi:10.1029/1999JC900215. remote data.

We hope that this easy web-access to paleo-model data will stimulate new model-data intercomparison studies focusing on the last glacial termination and the Holocene. Unrestricted access to transient paleoclimate simulations will facilitate the climatic interpretation of geobiochemical information from marine and terrestrial proxy archives. Independent validation of model simulations with proxy records will further help to test the robustness of the model results. The combination of both

Opsteegh, J.D., Haarsma, R.J., Selten, F.M. and Kattenberg, A. 1998: ECBILT: A dynamic alternative to mixed boundary conditions in ocean models, Tellus, 50A(3): 348-367, doi:10.1034/j.1600-0870.1998.t01-1-00007.

Timm, 0., and Timmermann, A. 2007: Simulation of the last 21,000 years using accelerated transient boundary conditions, Journal of Climate, 20(17): 4377-4401. doi: 10.1175/JCLI4237.1

Timm, O., Timmermann, A., Abe-Ouchi, A., Saito, F. and Segawa, T., 2008: On the definition of seasons in paleoclimate simulations with orbital forcing, Paleoceanography, 23: PA2221, doi:10.1029/2007PA001461.

Timmermann, A., Timm 0., Stott, L, and Menviel, L, 2008: The roles of $\mathrm{CO}_{2}$ and orbital forcing in driving southern hemispheric temperature variations during the last 21,000 years, accepted in Journal of Climate.

\section{High- to low-latitude teleconnections during glacial terminations associated with ENSO-like variability}

Leopoldo D. Pena ${ }^{1,2}$ and Isabel CaCho $^{1}$

'Department of Stratigraphy, Paleontology and Marine Geosciences, University of Barcelona, Spain;

${ }^{2}$ Now at Lamont Doherty Earth Observatory of Columbia University, Palisades, USA; leopoldo@ldeo.columbia.edu

\section{Long-term changes in ENSO-like dynamics during deglaciations are linked to southern high-latitude regions through atmospheric and oceanic teleconnection mechanisms.}

Many studies have recognized that EI Niño-Southern Oscillation (ENSO) variability influences climate patterns around the globe (Cane, 1998; Federov and Philander, 2000). This has led to considerable efforts to unravel the history of ENSO and establish its role in past global changes. An increasing number of studies point towards tropical regions, and more particularly to ENSO-like variability (i.e., long-term ENSO variability), as one of the missing pieces in the cause of the Pleistocene glacialinterglacial climate variability. However, evidence for the nature of long-term ENSO variability is still conflicting. In particular, periods of global deglaciation have not shown prevailing El Niño-like or La Niñalike conditions in the tropical Pacific (Beaufort et al., 2001; Koutavas et al., 2002, 2006; Stott et al., 2002). Discrepant evidence may result from the inherently limited temporal resolution and fragmentary nature of the different proxy records. Modeling studies have provided a framework for the ENSO-like variability associated with orbital variations (Cane, 1998, 2004; Clement et al., 1999, 2000; Zebiak and Cane, 1987) and highlight the potential role of orbital dynamics in forcing the ENSO-like variability, through the modulation of the annual cycle of sea surface temperature, atmospheric convection and inter-tropical convergence zone migration in the eastern tropical Pacific (ETP). Although their conceptual basis is sound, tropical climate models still lack more accurate representations of high-low latitude teleconnection mechanisms, partially due to a limited understanding of the processes involved. These limitations highlight the importance of paleo-records to provide informa- 